\title{
Health-Related Quality of Life in Athletes: A Systematic Review With Meta-Analysis
}

\author{
Megan N. Houston, PhD, ATC*; Matthew C. Hoch, PhD, ATC†; \\ Johanna M. Hoch, PhD, ATC $†$
}

\author{
*Keller Army Community Hospital, West Point, NY; †Old Dominion University, Norfolk, VA
}

Context: Assessment of health-related quality of life (HRQOL) after injury is important. Differences in HRQOL between nonathletes and athletes and between injured and uninjured athletes have been demonstrated; however, the evidence has not been synthesized.

Objective: To answer the following questions: (1) Does HRQOL differ among adolescent and collegiate athletes and nonathletes? (2) Does HRQOL differ between injured adolescent and collegiate athletes or between athletes with a history of injury and uninjured athletes or those without a history of injury?

Data Sources: We systematically searched CINAHL, MEDLINE, SPORTDiscus, and PubMed. A hand search of references was also conducted.

Study Selection: Studies were included if they used generic instruments to compare HRQOL outcomes between athletes and nonathletes and between uninjured and injured athletes. Studies were excluded if they did not use a generic instrument, pertained to instrument development, or included retired athletes or athletes with a chronic disease.

Data Extraction: We assessed study quality using the modified Downs and Black Index Tool. Bias-corrected Hedges $g$ effect sizes and $95 \%$ confidence intervals (Cls) were calculated.
The Strength of Recommendation Taxonomy (SORT) was used to determine the overall strength of the recommendation. A random-effects meta-analysis was performed for all studies using the composite or total score.

Data Synthesis: Eight studies with modified Downs and Black scores ranging from $70.6 \%$ to $88.4 \%$ were included. For question 1, the overall random-effects meta-analysis was weak (effect size $=0.27,95 \%$ confidence interval $=0.14,0.40 ; P<$ $.001)$. For question 2 , the overall random-effects meta-analysis was moderate (effect size $=0.68,95 \%$ confidence interval $=$ $0.42,0.95 ; P<.001)$.

Conclusions: Grade A evidence indicates that athletes reported better HRQOL than nonathletes and that uninjured athletes reported better HRQOL than injured athletes. However, the overall effect for question 1 was weak, suggesting that the differences between athletes and nonathletes may not be clinically meaningful. Clinicians should monitor HRQOL after injury to ensure that all dimensions of health are appropriately treated.

Key Words: patient-centered care, patient outcomes, athletic injuries

\section{Key Points}

- Health-related quality of life (HRQOL) assessed via generic instruments was better in athletes than in nonathletes, but the differences were small and may not be clinically meaningful.

- Athletes without a history of injury reported better HRQOL on generic instruments than did injured athletes.

- To ensure that all health dimensions are being properly assessed and treated, clinicians should monitor patients' HRQOL throughout treatment and perhaps after return to play.

- Given these differences on generic instruments, it will be prudent to investigate the use of region-specific and dimension-specific instruments in assessing HRQOL.

$\mathrm{P}$ articipation in interscholastic and intercollegiate athletics has increased roughly 34\% since 1980 and $15 \%$ over the past decade and a half, with approximately 8.2 million student-athletes competing in 2014. ${ }^{1,2}$ Despite the health benefits associated with physical activity, ${ }^{3,4}$ individuals are also at risk for sport-related injuries. $^{5-7}$ Each year, up to 4.3 million sport- or activityrelated injuries are treated in US emergency departments. ${ }^{8,9}$ Injury can cause a range of physical and psychosocial detriments, which are predominantly examined using clinician-based assessments such as range of motion and strength. However, these assessments do not provide insight into the patient's perception of his or her health status, ${ }^{10}$ nor do they always correlate with overall health status. ${ }^{11-16}$ Therefore, the focus has shifted to the incorporation of patient-based assessments, such as patient-reported outcomes (PROs), to measure the patient's experience and values after medical treatments, interventions, and practices. ${ }^{17}$

Professional orthopaedic and sports medicine organizations $^{18-21}$ have emphasized the need for clinicians to use PROs in addition to clinician-based assessments to further understand the consequences of injury and to determine treatment efficacy. The PROs are typically categorized as region specific, dimension specific, or generic. Regionspecific and dimension-specific PROs focus on a particular body region, disease, or health dimension. Examples include the International Knee Documentation Committee form, ${ }^{22}$ Foot and Ankle Ability Measure, ${ }^{23}$ and Disabilities of the Arm, Shoulder and Hand (DASH). ${ }^{24}$ Generic outcomes are broad in scope and focus on general aspects 
Table 1. Search Summary: Key Words and Search Terms Used

\begin{tabular}{|c|c|c|c|c|}
\hline Step & Search Terms & $\begin{array}{l}\text { Boolean } \\
\text { Operator }\end{array}$ & $\begin{array}{c}\text { EBSCO } \\
\text { Host }\end{array}$ & PubMed \\
\hline 1 & $\begin{array}{l}\text { Health-related } \\
\text { quality of life }\end{array}$ & & 28120 & 22715 \\
\hline 2 & $\begin{array}{l}\text { Adolescent } \\
\text { High school } \\
\text { Interscholastic } \\
\text { Adult } \\
\text { College } \\
\text { Intercollegiate } \\
\text { NCAA }\end{array}$ & OR & 4788012 & 5472455 \\
\hline 3 & Athletes & & 177178 & 23308 \\
\hline 4 & 1,3 & AND & 42 & 24 \\
\hline 5 & $1,2,3$ & AND & 34 & 24 \\
\hline Duplicates & & & & 20 \\
\hline
\end{tabular}

Abbreviation: NCAA, National Collegiate Athletic Association.

a Duplicates in EBSCO Host and PubMed.

of health-related quality of life (HRQOL), which encompasses social, physical, and psychological health components. ${ }^{25-27}$ Health-related quality of life has become an important component of health surveillance, and the use of PRO instruments enables clinicians to track HRQOL deficits postinjury. ${ }^{27}$

Several groups ${ }^{10,28-34}$ have used generic outcomes such as the Short Form-36 (SF-36), Pediatric Outcomes Data Collection Instrument (PODCI), and Pediatric Quality of Life Inventory (PedsQL) to measure HRQOL in athletes and nonathletes and the effect of sport-related injury on HRQOL. Although the evidence suggests that normative values for athletes differ from the general population ${ }^{28,30,33,34}$ and between injured and uninjured athletes, ${ }^{10,29,31,32}$ this evidence has not been synthesized. A synthesis of the existing evidence will provide us with a more thorough understanding of differences in these scores for future research and clinical practice. Therefore, the purpose of our systematic review was to answer the following questions: (1) Does HRQOL differ among adolescent and collegiate athletes and nonathletes? (2) Does HRQOL differ between injured adolescent and collegiate athletes or between athletes with a history of injury and uninjured athletes or those without a history of injury?

\section{METHODS}

\section{Search Strategy}

A computerized literature search was completed using EBSCO (CINAHL, MEDLINE, SPORTDiscus) and PubMed from inception through August 15, 2015 (Table 1). Two authors (M.N.H., J.M.H.) reviewed the articles obtained for inclusion. Titles and abstracts of all articles were screened using the criteria below. If the authors were uncertain about eligibility, the full text was screened. A hand search was performed on the reference lists of all screened articles.

\section{Criteria for Selecting Studies}

\section{Inclusion Criteria:}

- Studies comparing HRQOL outcomes in athletes and nonathletes or in injured athletes or those with a history of injury and uninjured athletes or those without a history of injury
- Participants in 1 or more groups were described as current interscholastic or intercollegiate athletes

- Uninjured athletes or athletes without a history of injury were defined as medically cleared for participation

- Injured participants were defined as having a self-reported recent injury or having a history of musculoskeletal injury or concussion

- Studies using generic self-reported instruments (eg, SF-36, PODCI) as the primary outcome measure

- Studies published in English

- Studies published in peer-reviewed journals

\section{Exclusion Criteria:}

- Studies that included only retired athletes

- Studies that limited participants to those with chronic diseases (eg, asthma)

- Studies that used only region-specific or dimension-specific instruments (eg, International Knee Documentation Committee form, Foot and Ankle Ability Measure, DASH)

- Studies that described the development of an instrument to assess HRQOL

- Case studies, conference proceedings, or review articles

\section{Assessment of Methodologic Quality}

We used the modified Downs and Black Quality Index Tool $(\mathrm{mDB})^{35}$ described previously ${ }^{36}$ to assess the methodologic quality of included studies. The $\mathrm{mDB}$ was selected based on the nature of the study designs (ie, cross sectional) included in this review. Other tools available to critically appraise the literature, such as the Physiotherapy Evidence Database (PEDro) Scale were not applicable as they were designed to appraise the methodologic quality of other study designs (ie, randomized controlled trials), and we identified only cross-sectional studies in the systematic search. The $\mathrm{mDB}$ index has demonstrated high internal consistency (Kuder-Richardson $20=0.89)$ and interrater reliability $(r=$ $0.75){ }^{35}$ Studies meeting $<60 \%$ of the criteria were deemed low quality; $60 \%$ to $74.9 \%$, moderate quality; and $\geq 75 \%$, high quality. ${ }^{36}$ Two reviewers (M.N.H., J.M.H.) independently assessed the included studies. A third reviewer (M.C.H.) was consulted if the initial 2 reviewers could not resolve their disagreement.

\section{Strength of Recommendation}

The strength of recommendation for the included studies was assessed using the Strength of Recommendation Taxonomy (SORT). ${ }^{37}$ The taxonomy consists of A, B, and $\mathrm{C}$ ratings. Grade $A$ represents consistent, good-quality, patient-oriented evidence. Grade $B$ represents inconsistent or limited-quality, patient-oriented evidence, and grade $C$ represents consensus for disease-oriented evidence.

\section{Data Extraction and Statistical Analysis}

The variables of interest for this systematic review were scores on generic PROs that assessed HRQOL. For question 1, studies that compared generic HRQOL outcomes between athletes and nonathletes were included. Instruments used were the SF-12, SF-36, PODCI, and PedsQL. For question 2, studies that compared generic HRQOL outcomes between injured athletes (or those with 
a history of injury) and uninjured athletes (or those with no history of injury) were included. Instruments used were the SF-36 and PODCI. For questions 1 and 2, if both domain and composite or total scores were provided, we included only the composite or total scores in the meta-analysis. In 1 instance, only domain data were presented; therefore, we used a pooled effect size (ES) that represented each composite score for the analyses. An overall randomeffects meta-analysis was performed for each question to examine differences in HRQOL between groups. Separate meta-analyses were performed with the composite score (physical component summary [PCS] and mental component summary [MCS]) and age (adolescent or collegiate) as moderator variables.

For all analyses, Hedges $g$ ES and 95\% confidence intervals (CIs) were calculated to identify the magnitude and precision of the difference for each comparison. ${ }^{38}$ For studies with nonparametric data, adaptation methods $^{39}$ were used to estimate the mean and variance. All ESs, 95\% CIs, and $P$ values were calculated in Comprehensive Meta-Analysis (version 2.0; Biostat, Inc, Englewood, NJ). A positive ES for question 1 indicated better HRQOL in athletes than in nonathletes. A positive ES for question 2 indicated better HRQOL in uninjured athletes than in injured athletes. Effect sizes were interpreted as weak $(<0.40)$, moderate $(0.41-0.69)$, or strong $(\geq 0.70){ }^{40}$

\section{Sensitivity Analysis for Assessment of Publication Bias}

We used a funnel plot to examine the likelihood of publication bias. Duval and Tweedie's trim-and-fill meth$\mathrm{od}^{38}$ was applied as an additional assessment to identify studies missing on the left side of the mean effect. The method of removing 1 study tested the stability of the cumulative effect across all comparisons. ${ }^{38}$

\section{RESULTS}

\section{Literature Search}

The initial search (Figure 1) retrieved 58 articles. Twenty duplicate articles were immediately removed. Of the 38 articles screened, 6 studies ${ }^{29-34}$ met the inclusion criteria and did not meet any of the exclusion criteria. Two additional studies ${ }^{10,28}$ were identified through the hand search, resulting in a total of 8 eligible studies, which were classified into athletes and nonathletes (Table 2) and uninjured and injured athletes (Table 3 ).

\section{Question 1: Does HRQOL differ between athletes and nonathletes?}

Five articles ${ }^{10,28,30,33,34}$ met the inclusion criteria for this question. Quality scores ranged from $70.6 \%$ to $82.4 \%$ with 3 high-quality ${ }^{10,33,34}(\geq 75 \%)$ and 2 moderate-quality 28,30 studies $(60 \%, 74.9 \%)$. The mean $\mathrm{mDB}$ score was $76.5 \% \pm$ $5.9 \%$. Four articles $28,30,33,34$ provided sufficient data for the calculation of ESs and 95\% CIs (Table 4). The overall random-effects meta-analysis for all composite or total score comparisons revealed a weak ES of $0.27(95 \% \mathrm{CI}=$ $0.14,0.40 ; P<.001$; Figure 2). Among the 3 studies $^{28,33,34}$ that had data available for analysis using a composite score (PCS or MCS) as the moderator variable, a difference was evident $(\mathrm{Q}=4.86, P=.03)$. The results revealed a weak effect of $0.03(95 \% \mathrm{CI}=-0.32,0.53 ; P=$ $.86)$ for the PCS and a moderate effect of $0.46(95 \% \mathrm{CI}=$ $0.31,0.61 ; P=.002)$ for the MCS. Four studies had data available for analysis using age (adolescent or collegiate) as the moderator variable and demonstrated no difference between groups $(\mathrm{Q}=0.19, P=.66)$. A weak effect was present for both adolescent $(0.24 ; 95 \% \mathrm{CI}=0.06,0.42 ; P$ $=.008)$ and collegiate $(0.30 ; 95 \% \mathrm{CI}=0.08,0.53 ; P=$ .008 ) athletes. Overall, grade A evidence (consistent findings of 3 high-quality and 2 moderate-quality studies) indicated that athletes reported better HRQOL than nonathletes. However, although the evidence is consistent, the ESs and 95\% CIs demonstrated an overall weak effect, which suggests these differences may not be clinically meaningful.

Publication Bias. The analysis indicated that publication bias was unlikely (Figure 3), and no missing studies to the left of the mean were identified, resulting in no change in the overall effect. In addition, the Orwin Fail-Safe N indicated that 14 through 21 additional studies (with the trivial Hedges $g$ set at $0.05-0.10$, mean Hedges $g$ in missing studies $=-0.10$ ) would be needed to nullify the overall effect.

Sensitivity Analysis. The 1-study-removed method revealed ESs ranging from 0.23 to 0.31 , with the lowest $95 \% \mathrm{CI}=0.09$ and the highest $95 \% \mathrm{CI}=0.44$. All $P$ values were $<.002$. Therefore, no single study substantially influenced the overall effect.

\section{Question 2: Does HRQOL differ between injured athletes (or those with a history of injury) and uninjured athletes (or those with no history of injury)?}

Five articles ${ }^{10,28,29,31,32}$ met the inclusion criteria for this question. Quality scores ranged from $70.6 \%$ to $88.2 \%$, with 3 high-quality ${ }^{10,29,32}(\geq 75 \%)$ and 2 moderate-quality ${ }^{28,31}$ studies $(60 \%, 74.9 \%)$. The $\mathrm{mDB}$ score for these articles was $77.6 \% \pm 7.7 \%$. All 5 articles ${ }^{10,28,29,31,32}$ provided sufficient data for the calculation of ESs. Effect sizes and 95\% CIs for all comparisons are shown in Table 5. The overall randomeffects meta-analysis for all composite or total comparisons revealed a moderate ES of $0.68(95 \% \mathrm{CI}=0.42,0.95 ; P<$ .001 ; Figure 4). Five articles ${ }^{10,28,29,31,32}$ had data available for the random-effects meta-analysis using a composite score as the moderator variable and demonstrated a difference $(\mathrm{Q}=8.92, P=.003)$. A strong effect of 0.85 $(95 \% \mathrm{CI}=0.40,1.29 ; P<.001)$ was observed for the PCS, and a weak effect of $0.15(95 \% \mathrm{CI}=0.03,0.26 ; P=.01)$ was observed for the MCS. Five studies had data available for the random-effects meta-analysis using age (adolescent or collegiate) as the moderator variable; we found no difference between groups $(\mathrm{Q}=3.52, P=.061)$. The results revealed a strong effect for adolescents $(1.65 ; 95 \% \mathrm{CI}=$ $0.29,3.01 ; P=.017)$ and a moderate effect for collegians $(0.34 ; 95 \% \mathrm{CI}=0.20,0.49 ; P<.001)$. Overall, grade A evidence ( 3 high-quality and 2 moderate-quality studies) showed that uninjured athletes reported better HRQOL than injured athletes.

Publication Bias. The analysis indicated that publication bias was likely (Figure 5), with 4 missing studies to the left of the mean, resulting in a change in the 


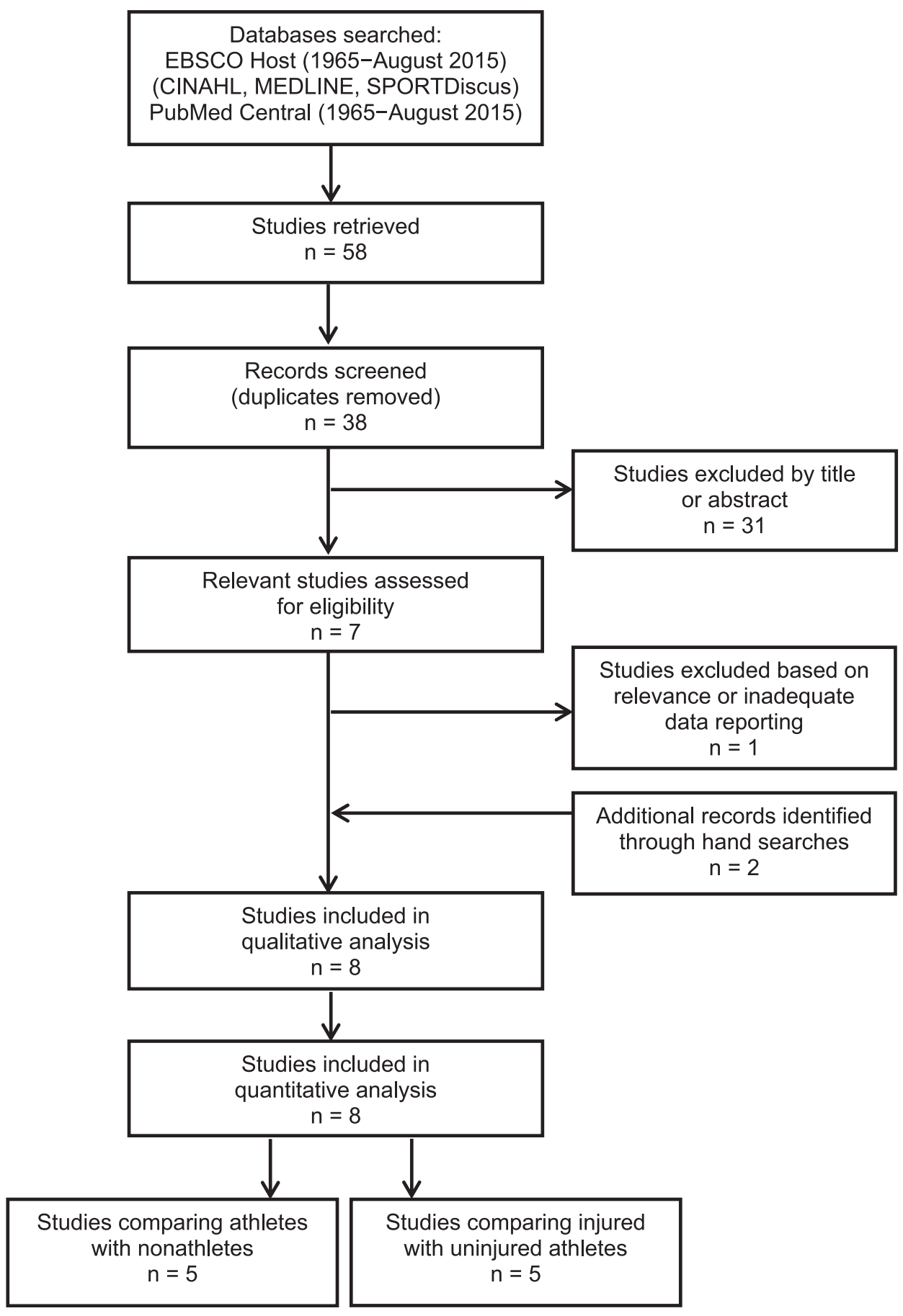

Figure 1. Flow chart of articles reviewed.

overall point estimate. The Orwin Fail-Safe N demonstrated that 18 through 31 additional studies (with the trivial Hedges $g$ set at $0.05-0.10$, mean Hedges $g$ in missing studies $=-0.10$ ) would be needed to nullify the overall effect.

Sensitivity Analysis. Following the 1-study-removed method, the ESs ranged from 0.48 to 0.73 , with the lowest $95 \% \mathrm{CI}=0.28$ and the highest $95 \% \mathrm{CI}=1.06$. All $P$ values were $\leq .001$. Thus, no 1 study substantially influenced the overall effect.

\section{DISCUSSION}

\section{Study Quality Assessment}

The mean $\mathrm{mDB}$ scores were $76.5 \% \pm 5.9 \%$ and $77.6 \%$ $\pm 7.7 \%$ for questions 1 and 2 , respectively. The criteria that did not receive a yes were a clear description of participant confounders, how representative the population asked to participate was of the population from which they were recruited, blinding of researchers who measured outcomes, whether or not the groups were from the same population, and whether statistical adjustments were made 
Table 2. Studies Systematically Reviewed to Determine if Health-Related Quality-of-Life Scores Were Higher in Athletes Than in Nonathletes $^{a}$

\begin{tabular}{|c|c|c|c|c|c|}
\hline Authors & $\begin{array}{l}\text { Quality Index } \\
\text { Score, \% }\end{array}$ & Inclusion Criteria & $\begin{array}{l}\text { Athletes, } \\
\text { No. }\end{array}$ & Nonathletes, No. & $\begin{array}{l}\text { Health-Related } \\
\text { Quality-of-Life Outcome }\end{array}$ \\
\hline Lam et $\mathrm{al}^{30}$ & 70.6 & $\begin{array}{l}\text { Adolescent (ages 14-18 y) } \\
\text { athletes cleared for } \\
\text { participation in an } \\
\text { interscholastic sport who did } \\
\text { not report current injury or } \\
\text { illness }\end{array}$ & 2659 & 1464 (Varni et $\left.\mathrm{al}^{41}\right)$ & Pediatric Quality of Life Inventory \\
\hline Huffman et $\mathrm{al}^{28}$ & 70.6 & $\begin{array}{l}\text { NCAA Division I and II athletes } \\
\text { cleared for participation }\end{array}$ & 696 & Normative data & SF-36 \\
\hline McAllister et $\mathrm{al}^{10}$ & 76.5 & $\begin{array}{l}\text { NCAA Division I collegiate } \\
\text { athletes who reported no } \\
\text { current injuries }\end{array}$ & 404 & Normative data & SF-36 \\
\hline
\end{tabular}

Abbreviations: NCAA, National Collegiate Athletic Association; SF-12, Short Form-12; SF-36, Short Form-36.

a All studies were cross sectional.

for confounding variables. These items can influence the internal and external validity of a study's findings. For example, adjusting for confounding variables such as years of athletic participation or number of injuries could provide a better interpretation of the findings. In addition, although blinding of assessors seems trivial when using PRO instruments, knowledge of injury history may cause the assessor to describe the instrument differently or influence responses to certain questions for each participant. Finally, it is vital that participants are from the same general population. For some of the included studies, the nonathlete groups consisted of population norms that were poorly described or participants who were not recruited from the same institution (or both). Future researchers should identify confounders and adjust for these variables. Additionally, making efforts to blind assessors and recruit from similar populations is warranted to enhance validity.

\section{Question 1: Did HRQOL differ between athletes and nonathletes?}

Five included studies ${ }^{10,28,30,33,34}$ compared generic HRQOL outcomes between athletes and nonathletes. This systematic review provided grade A evidence that HRQOL was better in athletes than in nonathletes. However, although the evidence was consistent, the ESs and 95\% CIs demonstrated an overall weak effect, which suggests these differences may not be clinically meaningful. When we examined all 46 individual ESs (Table 4), only 17 point

Table 3. Studies Systematically Reviewed to Determine if Health-Related Quality of Life Scores Were Higher in Injured Athletes Than in Uninjured Athletes ${ }^{a}$

\begin{tabular}{|c|c|c|c|c|c|}
\hline Study & $\begin{array}{l}\text { Quality Index } \\
\text { Score, \% }\end{array}$ & Inclusion Criteria & $\begin{array}{c}\text { Injured } \\
\text { Athletes, No. }\end{array}$ & $\begin{array}{c}\text { Uninjured } \\
\text { Athletes, No. }\end{array}$ & $\begin{array}{c}\text { Health-Related } \\
\text { Quality of Life Outcome }\end{array}$ \\
\hline Huffman et al ${ }^{28}$ & 70.6 & $\begin{array}{l}\text { NCAA Division I and II athletes } \\
\text { who reported a previous injury } \\
\text { but were cleared for active } \\
\text { participation at time of survey } \\
\text { administration }\end{array}$ & 390 & 244 & SF-36 \\
\hline Kuehl et al ${ }^{29}$ & 82.4 & $\begin{array}{l}\text { Intercollegiate athletes with self- } \\
\text { reported history of concussion }\end{array}$ & 133 & 169 & SF-36 \\
\hline Valovich McLeod et $\mathrm{al}^{31}$ & 70.6 & $\begin{array}{l}\text { Adolescent athletes with self- } \\
\text { reported history of injury within } \\
\text { past week }\end{array}$ & 45 & 160 & $\begin{array}{l}\text { SF-36 } \\
\text { Pediatric Outcomes Data } \\
\quad \text { Collection Instrument }\end{array}$ \\
\hline Valovich McLeod et al ${ }^{32}$ & 88.2 & $\begin{array}{l}\text { High school students with self- } \\
\text { reported history of concussion }\end{array}$ & 140 & 126 & SF-36 \\
\hline
\end{tabular}

Abbreviations: NCAA, National Collegiate Athletic Association; SF-36, Short Form-36.

a All studies were cross sectional. 
Table 4. Effect Sizes and 95\% Confidence Intervals for Question 1, "Does Health-Related Quality of Life Differ Between Athletes and Nonathletes?"

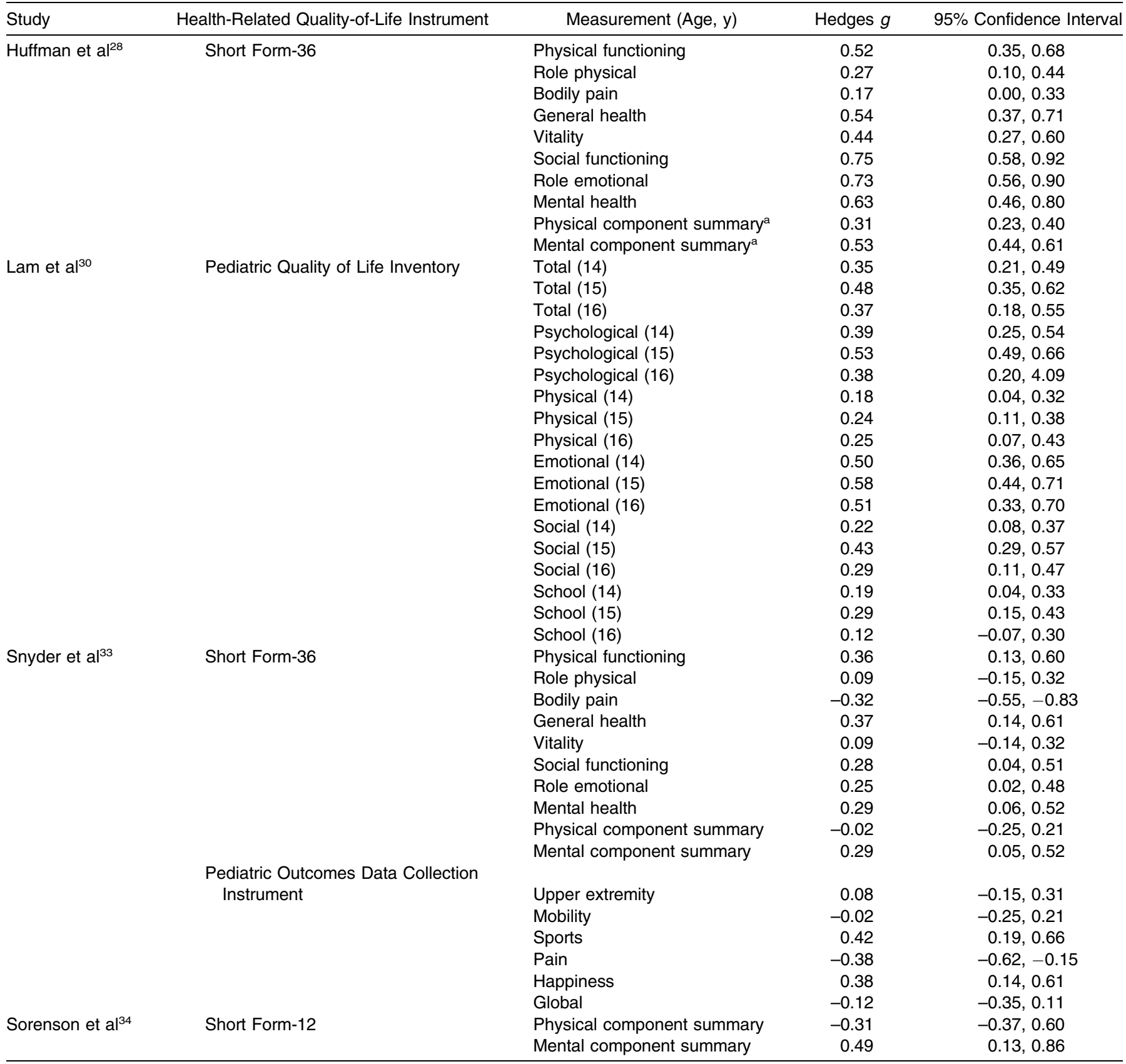

a Physical and mental component summary scores were calculated using Comprehensive Meta-Analysis software (Biostat, Inc, Englewood, NJ). Component summary scores were used in all analyses.

estimates were considered moderate or strong. Thus, even though the positive ESs indicated HRQOL differences, the interpretation of the strength of the ESs and the overall ES from the meta-analysis demonstrated a weak difference between groups. The positive ESs imply that involvement in athletics may benefit overall health status, yet the small magnitude of the differences suggests that normative values for HRQOL in a nonathletic cohort may be a suitable reference for athletic cohorts, contrary to what has been previously thought. ${ }^{42-44}$ The statistical differences detected could have been confounded by the sample size; in other words, the actual difference between the athletes and nonathletes, or the overall effect, was weak. Therefore, HRQOL differences may not occur between athletes and nonathletes, suggesting that, until we have additional evidence, using normative values appears to be acceptable. However, the normative values should be from a sample similar in age to the population. Ultimately, baseline values should be obtained to establish a true point of comparison for the individual.

For question 1, 3 studies ${ }^{10,28,34}$ compared SF-36 or SF-12 outcomes between collegiate athletes and nonathletes. In a sample of 562 National Collegiate Athletic Association Division I athletes, emotional role $(P<.001)$ and mental 


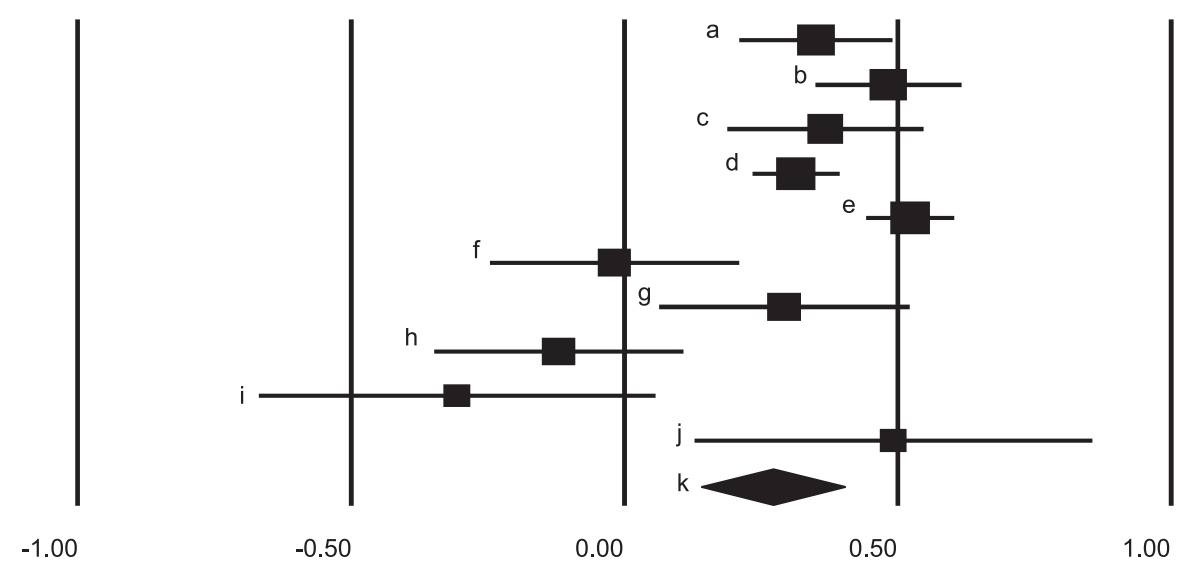

Favors Nonathletes

Favors Athletes

\begin{tabular}{|c|c|c|c|c|c|}
\hline \multirow[b]{2}{*}{ Study Name } & \multirow[b]{2}{*}{ Subgroup Within Study } & \multirow[b]{2}{*}{ Hedges $g$} & \multicolumn{2}{|c|}{ Statistics } & \multirow[b]{2}{*}{$P$ Value } \\
\hline & & & Lower Limit & Upper Limit & \\
\hline a. Lam et $\mathrm{al}^{30}$ & PedsQL Total (age 14) & 0.350 & 0.207 & 0.494 & $<.001$ \\
\hline b. Lam et $\mathrm{al}^{30}$ & PedsQL Total (age 15) & 0.483 & 0.346 & 0.620 & $<.001$ \\
\hline c. Lam et $\mathrm{al}^{30}$ & PedsQL Total (age 16) & 0.368 & 0.185 & 0.550 & $<.001$ \\
\hline d. Huffman et $\mathrm{al}^{28}$ & PCS Combined & 0.314 & 0.230 & 0.397 & $<.001$ \\
\hline e. Huffman et $\mathrm{al}^{28}$ & MCS Combined & 0.523 & 0.439 & 0.607 & $<.001$ \\
\hline f. Snyder et al ${ }^{33}$ & PCS & -0.018 & -0.249 & 0.214 & .880 \\
\hline g. Snyder et al $^{33}$ & MCS & 0.293 & 0.060 & 0.525 & .014 \\
\hline h. Snyder et al ${ }^{33}$ & PODCI Global & 0.120 & -0.352 & 0.112 & .310 \\
\hline i. Snyder et $\mathrm{al}^{33}$ & PCS & -0.306 & -0.672 & 0.060 & .101 \\
\hline j. Snyder et al ${ }^{33}$ & MCS & 0.492 & 0.125 & 0.859 & .009 \\
\hline k. Overall effect & & 0.267 & 0.136 & 0.398 & $<.001$ \\
\hline
\end{tabular}

Figure 2. Forest plot demonstrating the individual point estimates and overall effect sizes for question 1, "Does health-related quality of life differ between athletes and nonathletes?" Abbreviations: MCS, mental component summary; PCS, physical component summary; PedsQL, Pediatric Quality of Life Inventory; PODCI, Pediatric Outcomes Data Collection Instrument.

health $(P<.002)$ were increased when compared with sexmatched and age-matched norms of the general US population. ${ }^{10}$ In a larger sample $(\mathrm{n}=696),{ }^{28}$ collegiate athletes exhibited better HRQOL on all domains of the SF36 except for bodily pain $(P=.05)$ than a similar-aged sample from the US general population. Authors of both studies ${ }^{10,28}$ concluded that athletes exhibited better HRQOL compared with normative data for the general population. We could not calculate ESs for 1 study, ${ }^{10}$ and strong ESs were present for only 2 domains (SF-36 role emotional and SF-36 social function) in the other study. ${ }^{28}$ Furthermore, when domain ESs were pooled, a weak effect for the PCS and a moderate effect for the MCS were identified. ${ }^{28}$ In contrast, Sorensen et $\mathrm{al}^{34}$ reported a negative weak effect for the SF-12 PCS and a moderate effect for the MCS, suggesting that nonathletes had better HRQOL as measured by the PCS and athletes had better HRQOL as measured by the MCS. Interestingly, these researchers ${ }^{34}$ provided extensive demographic data for their 2 groups, including age, body mass index, and ethnicity. The differences noted between these 2 groups were possibly due to the similarities of the groups being compared versus the normative data used in previous studies. ${ }^{28}$ Future investigators should include comparison groups representative of the individuals in the athletic group with respect to demographics (in addition to age) in order to examine the magnitude of difference between groups.
The other 2 studies $^{30,33}$ that were included for question 1 compared HRQOL in adolescent athletes and nonathletes. Both groups concluded that adolescent athletes reported greater generic HRQOL; however, the point estimates for the SF-36, PODCI, and PedsQL and domains and

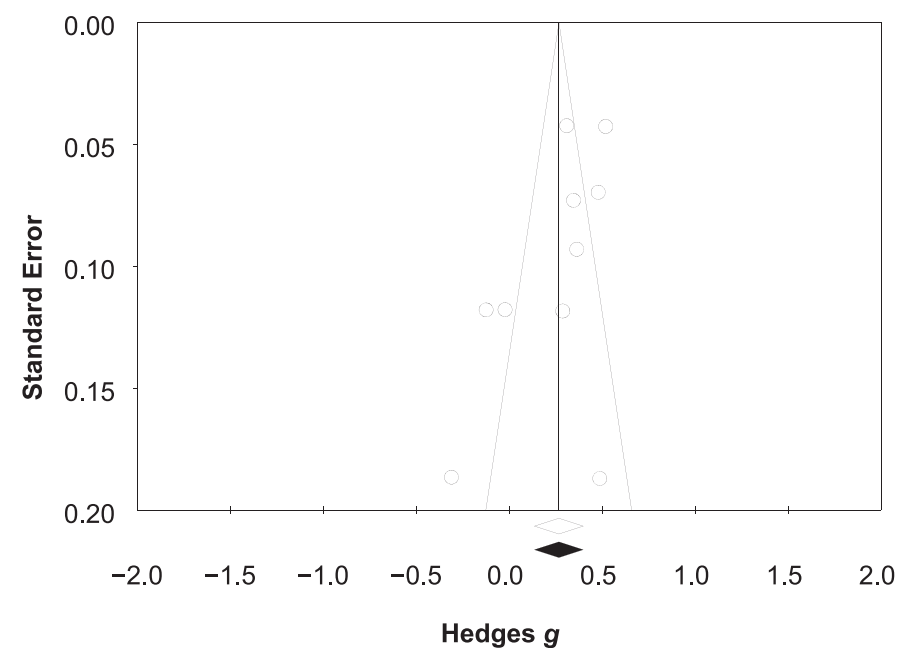

Figure 3. Funnel plot demonstrating that publication bias was unlikely for question 1, "Does health-related quality of life differ between athletes and nonathletes?" Note: The black diamond represents the adjusted cumulative effect. 
composite scores were primarily weak and had wide $95 \%$ CIs. Therefore, this meta-analysis demonstrated that adolescent athletes and nonathletes may have similar HRQOL as measured by generic PROs. The PODCI and PedsQL data points were not included in the meta-analysis with composite scores as a moderator variable. However, consistent with the results of the meta-analysis using composite scores as moderator variables, adolescent athletes reported better HRQOL on the subscales pertaining to mental and emotional well-being (PedsQL-Emotional, PedsQL-Psychological) in comparison with nonathletes. In contrast, adolescent nonathletes reported better HRQOL on subscales pertaining to physical well-being (PODCI-Pain, PODCI-Mobility), a result that is similar to the overall meta-analysis results for PCS scores. We believe that athletes may perceive the physical components of HRQOL, such as bodily pain and basic mobility, differently than nonathletes due to the demanding movement patterns required in sports, potentially restrictive equipment, and the physical effects of sports on the body (eg, delayed-onset muscle soreness, sport-related injury).

\section{Question 2: Did HRQOL differ between injured athletes (or those with a history of injury) and uninjured athletes (or those with no history of injury)?}

Five studies ${ }^{10,28,29,31,32}$ included in this review compared generic HRQOL outcomes between these groups. This systematic review provided grade A evidence that HRQOL was better in uninjured athletes than in injured athletes. The overall ES was moderate, with a $95 \%$ CI that did not cross zero. Therefore, HRQOL did appear to be higher in uninjured athletes (or athletes without a history of injury) compared with injured athletes (or athletes with a history of injury); the strongest ESs were observed in athletes with a current injury. The differences between these groups suggest that injury negatively affects overall health status.

For question 2, 3 studies ${ }^{10,28,29}$ compared generic HRQOL outcomes in collegiate athletes. Huffman et $\mathrm{al}^{28}$ reported that athletes with no history of injury exhibited better HRQOL in 7 of 8 SF-36 domains and both composite scores compared with athletes who had a history of injury. However, all but 1 of the ESs were interpreted as weak. It must be noted that the authors did not define injury history or classify the severity of injury history for the injured group, and these unexplained demographics could have affected the point estimates. McAllister et $\mathrm{al}^{10}$ noted that athletes who were uninjured at the time of data collection had higher HRQOL scores on the SF-36 than did athletes with a significant or mild injury. Mild was defined as an injury that had minimal or no effect on participation, practice, or play. ${ }^{10}$ Serious was defined as an injury that had a significant effect on participation, practice, or play or resulted in the inability to participate. ${ }^{10}$ The PCS ESs and 95\% CIs for the composite scores of those with serious injuries were strong for both males and females across the groups (mild or serious injury). The PCS ESs for those with mild injuries were strong, but the 95\% CIs ranged from weak to strong. The MCS ESs for both sexes were weak to moderate, and CIs ranged from weak to strong for those with serious injuries. The MCS ESs and 95\% CIs for both sexes were weak for the mild-injury comparisons. One group $^{29}$ examined differences between athletes with 1 to 2 or $\geq 3$ concussions and those without a history of concussion. Athletes injured at the time of data collection were excluded. Even though all 4 of the composite point estimates were positive, the $95 \%$ CIs crossed zero, suggesting that these findings should be interpreted with caution. However, the number of previous concussions may influence HRQOL, as ESs were larger for athletes with $\geq 3$ concussions as opposed to individuals with a history of 1 to 2 concussions. Although the definition of injured athlete varied among these 3 studies, the evidence shows that uninjured athletes reported better HRQOL than did collegiate athletes with a current injury, history of musculoskeletal injury, or history of sport-related concussion. Future researchers should further investigate how the severity of injury history affects HRQOL when compared with athletes who incurred less severe injuries or athletes who had no history of injury.

Two groups ${ }^{31,32}$ compared HRQOL in injured and uninjured adolescent athletes. The same primary investigator compared adolescent athletes who had a recent musculoskeletal injury with uninjured athletes ${ }^{31}$ and athletes who had a self-reported history of concussion with athletes who had no history of concussion. ${ }^{32}$ Interestingly, for the PCS and PODCI-Global composite score, the ESs and $95 \%$ CIs for the recently injured athletes were strong. ${ }^{31}$ However, the MCS point estimate was weak, with a weak to moderate $95 \% \mathrm{CI}$. These data suggest that injuries may affect the physical components of HRQOL more than the mental components, and these results appear to be consistent across age in athletes. Furthermore, the results of our meta-analysis with composite score as a moderator variable also support this conclusion, as the PCS point estimate was strong, and the MCS point estimate was weak, yet when HRQOL scores were compared between adolescent athletes with a history of concussion and those with no history of concussion, the point estimates for both the MCS and PCS were weak, and the $95 \%$ CI for the PCS crossed zero. Based on these findings, in conjunction with the composite point estimates of Kuehl et al, ${ }^{29}$ concussion history may have a minimal effect on generic HRQOL. However, it must be noted that the musculoskeletal injury history of the group without a history of concussion was not reported. It may be that the athletes in the group without a history of concussion had a history of musculoskeletal injury. Future researchers should further investigate the effect of concussion history on HRQOL by including athletes without a history of injury.

Our additional analysis using age as a moderator variable revealed no difference between groups. Therefore, for all analyses, we pooled the adolescent and collegiate data, yet based on the results for question 1 and additional analysis performed for question 2, we propose including similaraged patients or cohorts when investigating this phenomenon.

\section{Limitations}

Although this systematic review was completed using the Preferred Reporting Items for Systematic Reviews and Meta-Analyses (PRISMA) guidelines, limitations were present. The electronic searches were conducted in databases considered the most relevant to the questions. The search was also limited to peer-reviewed studies 
Table 5. Effect Sizes and 95\% Confidence Intervals for Question 2, "Does Health-Related Quality of Life Differ Between Injured Athletes and Uninjured Athletes?" Continued on Next Page

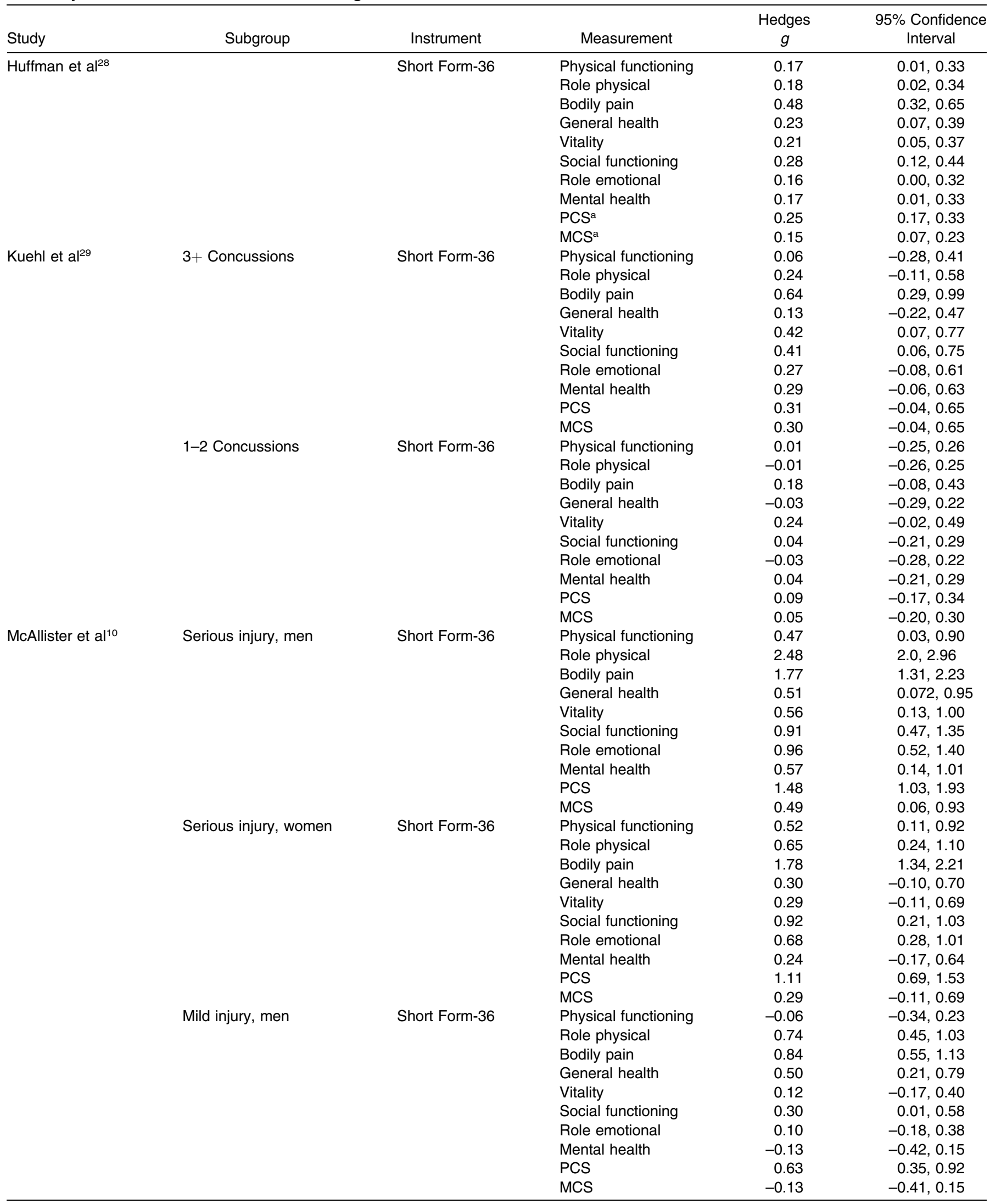




\begin{tabular}{|c|c|c|c|c|c|}
\hline Study & Subgroup & Instrument & Measurement & $\begin{array}{c}\text { Hedges } \\
g\end{array}$ & $\begin{array}{l}\text { 95\% Confidence } \\
\text { Interval }\end{array}$ \\
\hline & Mild injury, women & Short Form-36 & Physical functioning & 0.08 & $-0.25,0.40$ \\
\hline & & & Role physical & 0.30 & $-0.02,0.62$ \\
\hline & & & General health & 0.30 & $-0.01,0.63$ \\
\hline & & & Vitality & -0.08 & $-0.40,0.27$ \\
\hline & & & Social functioning & 0.25 & $-0.07,0.57$ \\
\hline & & & PCS & 0.61 & $0.28,0.93$ \\
\hline & & & MCS & -0.17 & $-0.49,0.16$ \\
\hline \multirow[t]{12}{*}{ Valovich McLeod et al ${ }^{31}$} & & Short Form-36 & Physical functioning & 2.61 & $2.20,3.03$ \\
\hline & & & Role physical & 3.44 & $2.97,3.91$ \\
\hline & & & Bodily pain & 4.94 & $4.36,5.52$ \\
\hline & & & General health & -0.18 & $-0.51,0.15$ \\
\hline & & & PCS & 3.34 & $2.88,3.80$ \\
\hline & & & MCS & 0.21 & $-0.12,0.54$ \\
\hline & & Pediatric Outcomes Data & Upper extremity & 2.13 & $1.74,2.52$ \\
\hline & & Collection Instrument & Mobility & 2.13 & $1.74,2.52$ \\
\hline & & & Sports & 2.16 & $1.77,2.56$ \\
\hline & & & Pain & 5.44 & $4.82,6.06$ \\
\hline & & & Happiness & 0.67 & $0.33,1.00$ \\
\hline & & & Global & 4.44 & $3.86,4.93$ \\
\hline \multirow[t]{4}{*}{ Valovich McLeod et al ${ }^{32}$} & & Short Form-36 & Physical functioning & -0.15 & $-0.39,0.09$ \\
\hline & & & Role physical & 0.05 & $-0.19,0.29$ \\
\hline & & & Bodily pain & 0.38 & $0.14,0.62$ \\
\hline & & & General health & 0.23 & $-0.02,0.47$ \\
\hline
\end{tabular}

Abbreviations: MCS, mental component summary; PCS, physical component summary.

a Physical and mental component summary scores were calculated using Meta-Analysis software (Biostat, Inc, Englewood, NJ). Component summary scores were used in all analyses.

published in English. It is possible that other evidence is available; however, we do not believe relevant articles were excluded using these search guidelines. Second, nonparametric data were converted to parametric data to enable calculation of ESs. ${ }^{31}$ Furthermore, 1 group ${ }^{28}$ did not report summary component scores for the SF-36, so we computed ESs for the domains and included them in the analyses. Subscale scores from the other studies were removed from the analyses to avoid redundancy and violation of power. Additionally, we could not calculate ESs for McAllister et $\mathrm{al}^{10}$ data for question 1 .

\section{CONCLUSIONS}

A systematic search of the literature revealed 8 studies that compared HRQOL outcomes in athletes and nonathletes and injured and uninjured athletes. All 5 studies comparing HRQOL in athletes and nonathletes demonstrated positive ESs, indicating that athletes reported better HRQOL on generic instruments, yet the strength of the ESs for most comparisons was weak, suggesting that the statistical differences noted in these studies may not be clinically meaningful. If baseline values were not obtained before injury, we recommend clinicians use normative values from populations that resemble the patient. In the 5 studies that compared HRQOL in injured and uninjured athletes, uninjured athletes or athletes without a history of injury reported better HRQOL on generic instruments. Further analysis revealed that injury may affect the physical components of HRQOL and have a minimal effect on the mental components of HRQOL. We believe these data indicate that clinicians should monitor HRQOL in patients after injury, throughout treatment, and possibly after return to activity to ensure all dimensions of health are appropriately assessed and treated. Furthermore, knowing HRQOL differences exist on generic instruments should promote the use of region-specific and dimension-specific instruments in research and clinical care. Future investigators should continue to examine these phenomena in region-specific and dimension-specific instruments in similar groups. 


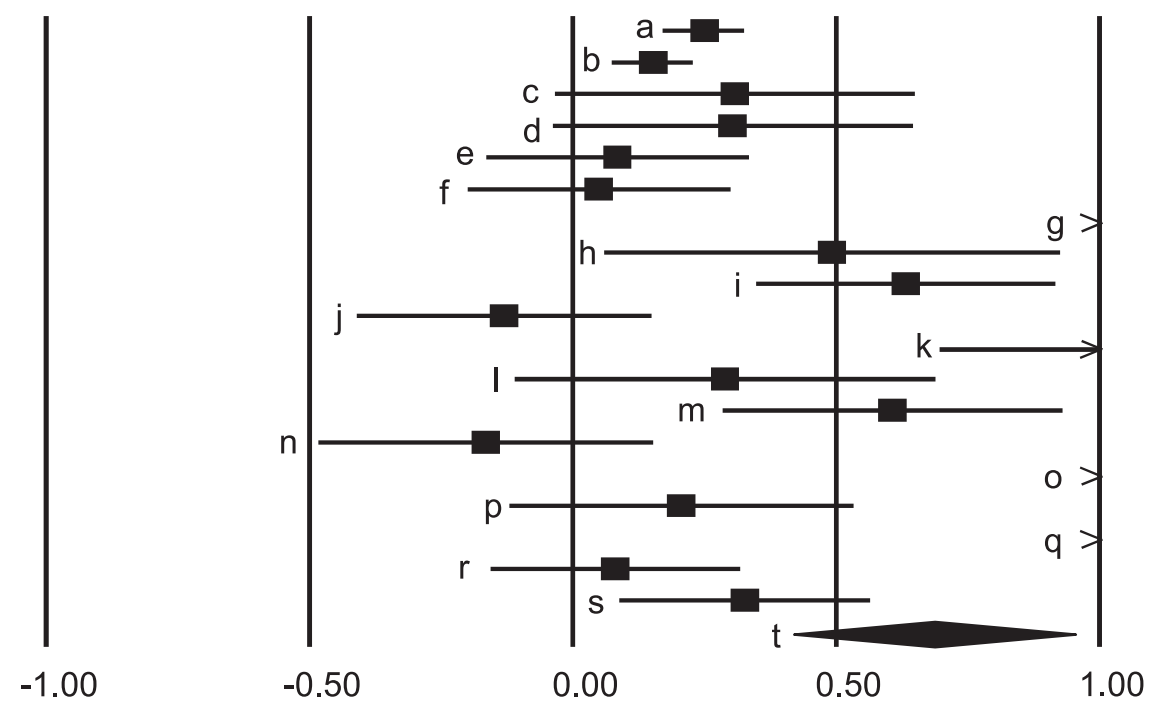

Favors Uninjured Athletes Favors Injured Athletes

\begin{tabular}{|c|c|c|c|c|c|}
\hline \multirow[b]{2}{*}{ Study Name } & \multirow[b]{2}{*}{ Subgroup Within Study } & \multirow{2}{*}{$\begin{array}{c}\text { Hedges } \\
g\end{array}$} & \multicolumn{2}{|c|}{ Statistics } & \multirow{2}{*}{$\begin{array}{c}P \\
\text { Value }\end{array}$} \\
\hline & & & Lower Limit & Upper Limit & \\
\hline a. Huffman et al ${ }^{28}$ & Combined PCS & 0.250 & 0.170 & 0.331 & $<.001$ \\
\hline b. Huffman et al $^{28}$ & Combined MCS & 0.153 & 0.073 & 0.233 & $<.001$ \\
\hline c. Kuehl et $\mathrm{al}^{29}$ & PCS 3+ & 0.308 & -0.037 & 0.652 & .080 \\
\hline d. Kuehl et al ${ }^{29}$ & MSC 3+ & 0.303 & -0.041 & 0.648 & .085 \\
\hline e. Kuehl et $\mathrm{al}^{29}$ & PCS 1-2 & 0.085 & -0.167 & 0.337 & .510 \\
\hline f. Kuehl et $\mathrm{al}^{29}$ & MCS 1-2 & 0.049 & -0.203 & 0.302 & .701 \\
\hline g. McAllister et $\mathrm{al}^{10}$ & PCS SER MEN & 1.480 & 1.028 & 1.931 & $<.001$ \\
\hline h. McAllister et $\mathrm{al}^{10}$ & MSC SER MEN & 0.492 & 0.056 & 0.929 & .027 \\
\hline i. McAllister et $\mathrm{al}^{10}$ & PCS MILD MEN & 0.632 & 0.345 & 0.919 & $<.001$ \\
\hline j. McAllister et al ${ }^{10}$ & MCS MILD MEN & -0.131 & -0.414 & 0.152 & .365 \\
\hline k. McAllister et al ${ }^{10}$ & PCS SER WOM & 1.111 & 0.693 & 1.528 & $<.001$ \\
\hline I. McAllister et $\mathrm{al}^{10}$ & MCS SER WOM & 0.289 & -0.114 & 0.691 & .159 \\
\hline m. McAllister et $a^{10}$ & MCS MILD WOM & 0.607 & 0.281 & 0.933 & $<.001$ \\
\hline n. McAllister et $\mathrm{al}^{10}$ & PCS MILD WOM & -0.165 & -0.486 & 0.156 & .313 \\
\hline o. Valovich McLeod et al ${ }^{31}$ & PCS & 3.340 & 2.878 & 3.801 & $<.001$ \\
\hline p. Valovich McLeod et $a^{31}$ & MCS & 0.206 & -0.124 & 0.536 & .221 \\
\hline q. Valovich McLeod et al ${ }^{31}$ & PODCI Global & 4.390 & 3.852 & 4.927 & $<.001$ \\
\hline r. Valovich McLeod et al ${ }^{32}$ & PCS & 0.081 & -0.159 & 0.321 & .510 \\
\hline s. Valovich McLeod et $\mathrm{al}^{32}$ & MCS & 0.326 & 0.085 & 0.568 & .008 \\
\hline t. Overall effect & & 0.682 & 0.415 & 0.949 & $<.001$ \\
\hline
\end{tabular}

Figure 4. Forest plot demonstrating the individual point estimates and overall effect size for question 2, "Does health-related quality of life differ between injured athletes and uninjured athletes?" Abbreviations: MCS, mental component summary; PCS, physical component summary; PODCI, Pediatric Outcomes Data Collection Instrument; SER, serious injury; WOM, women.

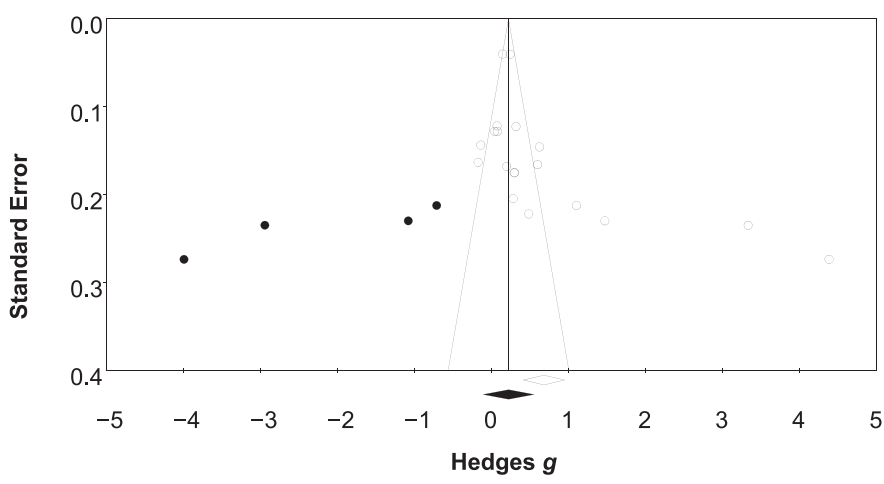

Figure 5. Funnel plot demonstrating that publication bias was likely for question 2, "Does health-related quality of life differ between injured athletes and uninjured athletes?" Note: The 4 black circles were added using the trim-and-fill method to balance the symmetry. The black diamond represents the adjusted cumulative effect.

\section{REFERENCES}

1. Student-athlete participation 1981-1982-2013-2014: NCAA sports sponsorship and participation rates report. National Collegiate Athletic Association Web site. http://www.ncaapublications.com/ productdownloads/PR1314.pdf. Published 2014. Accessed April 14, 2014.

2. 2014-2015 High school athletics participation survey. National Federation of State High School Associations Web site. http://www. nfhs.org/ParticipationStatics/PDF/2014-15_Participation_Survey_ Results.pdf. Published 2015. Accessed April 14, 2014.

3. Janssen I, LeBlanc AG. Systematic review of the health benefits of physical activity and fitness in school-aged children and youth. Int $J$ Behav Nutr Phys Act. 2010;7:40.

4. Warburton DE, Nicol CW, Bredin SS. Health benefits of physical activity: the evidence. CMAJ. 2006;174(6):801-809.

5. Conn JM, Annest JL, Gilchrist J. Sports and recreation related injury episodes in the US population, 1997-99. Inj Prev. 2003;9(2):117123. 
6. Hootman JM, Macera CA, Ainsworth BE, Martin M, Addy CL, Blair SN. Association among physical activity level, cardiorespiratory fitness, and risk of musculoskeletal injury. Am J Epidemiol. 2001; 154(3):251-258.

7. Nauta J, Martin-Diener E, Martin BW, van Mechelen W, Verhagen E. Injury risk during different physical activity behaviours in children: a systematic review with bias assessment. Sports Med. 2015;45(3):327-336.

8. Centers for Disease Control and Prevention (CDC). Nonfatal sportsand recreation-related injuries treated in emergency departmentsUnited States, July 2000-June 2001. MMWR Morb Mortal Wkly Rep. 2002;51(33):736-740.

9. NEISS: National Electronic Injury Surveillance System. United States Consumer Product Safety Commission Web site. http://www. cpsc.gov/en/Research-Statistics/NEISS-Injury-Data. Published 2012. Accessed October 5, 2015.

10. McAllister DR, Motamedi AR, Hame SL, Shapiro MS, Dorey FJ. Quality of life assessment in elite collegiate athletes. Am J Sports Med. 2001;29(6):806-810.

11. Binkley J. Measurement of functional status, progress and outcome in orthopaedic clinical practice. Orthop Phys Ther Pract. 1999;11(1): $14-21$.

12. Wilson IB, Cleary PD. Linking clinical variables with health-related quality of life: a conceptual model of patient outcomes. JAMA. 1995; 273(1):59-65.

13. Bruyere O, Honore A, Rovati LC, et al. Radiologic features poorly predict clinical outcomes in knee osteoarthritis. Scand J Rheumatol. 2002;31(1):13-16.

14. Dawes DJ, Meterissian S, Goldberg M, Mayo NE. Impact of lymphoedema on arm function and health-related quality of life in women following breast cancer surgery. J Rehabil Med. 2008;40(8): $651-658$.

15. Tomaino MM, Miller RJ, Burton RI. Outcome assessment following limited wrist fusion: objective wrist scoring versus patient satisfaction. Contemp Orthop. 1994;28(5):403-410.

16. van der Stouwe A, Broersma M, Buijink AW, Van Rootselaar AF, Maurits NM. Limited correlations between clinician-based and patient-based measures of essential tremor severity. Parkinsonism Relat Disord. 2015;21(6):654-657.

17. Valovich McLeod TC, Snyder AR, Parsons JT, Curtis Bay R, Michener LA, Sauers EL. Using disablement models and clinical outcomes assessment to enable evidence-based athletic training practice, part II: clinical outcomes assessment. J Athl Train. 2008; 43(4):437-445.

18. Rineberg BA. A call to leadership. The role of orthopaedic surgeons in musculoskeletal outcomes research. J Bone Joint Surg Am. 1990; 72(10): 1439-1440.

19. Rineberg BA. Managing change during complex times. J Bone Joint Surg Am. 1990;72(6):799-800.

20. Johnson RJ. Outcomes research in the AOSSM. Am J Sports Med. 1994;22(6):734-738

21. Hertel J. Research training for clinicians: the crucial link between evidence-based practice and third-party reimbursement. J Athl Train. 2005;40(2):69-70.

22. Irrgang JJ, Anderson AF. Development and validation of healthrelated quality of life measures for the knee. Clin Orthop Relat Res. 2002;402:95-109.

23. Martin RL, Irrgang JJ, Burdett RG, Conti SF, Van Swearingen JM. Evidence of validity for the foot and ankle ability measure (FAAM). Foot Ankle Int. 2005;26(11):968-983.

24. Hudak PL, Amadio PC, Bombardier C. Development of an upper extremity outcome measure: the DASH (Disabilities of the Arm,
Shoulder and Hand) [corrected]. The Upper Extremity Collaborative Group (UECG). Am J Ind Med. 1996;29(6):602-608.

25. Guyatt GH, Feeny DH, Patrick DL. Measuring health-related quality of life. Ann Intern Med. 1993;118(8):622-629.

26. Patrick DL, Deyo RA. Generic and disease-specific measures in assessing health status and quality of life. Med Care. 1989;27(suppl 3):S217-S232.

27. Parsons JT, Snyder AR. Health-related quality of life as a primary clinical outcome in sport rehabilitation. $J$ Sport Rehabil. 2011;20(1): $17-36$.

28. Huffman GR, Park J, Roser-Jones C, Sennett BJ, Yagnik G, Webner D. Normative SF-36 values in competing NCAA intercollegiate athletes differ from values in the general population. $J$ Bone Joint Surg Am. 2008;90(3):471-476.

29. Kuehl MD, Snyder AR, Erickson SE, McLeod TC. Impact of prior concussions on health-related quality of life in collegiate athletes. Clin J Sport Med. 2010;20(2):86-91.

30. Lam KC, Valier AR, Bay RC, McLeod TC. A unique patient population? Health-related quality of life in adolescent athletes versus general, healthy adolescent individuals. J Athl Train. 2013; 48(2):233-241.

31. Valovich McLeod TC, Bay RC, Parsons JT, Sauers EL, Snyder AR. Recent injury and health-related quality of life in adolescent athletes. $J$ Athl Train. 2009;44(6):603-610.

32. Valovich McLeod TC, Bay RC, Snyder AR. Self-reported history of concussion affects health-related quality of life in adolescent athletes. Athl Train Sports Health. 2010;2(5):219-226.

33. Snyder AR, Martinez JC, Bay RC, Parsons JT, Sauers EL, Valovich McLeod TC. Health-related quality of life differs between adolescent athletes and adolescent nonathletes. J Sport Rehabil. 2010;19(3): 237-248.

34. Sorenson SC, Romano R, Scholefield RM, et al. Holistic life-span health outcomes among elite intercollegiate student-athletes. $J$ Athl Train. 2014;49(5):684-695.

35. Downs SH, Black N. The feasibility of creating a checklist for the assessment of the methodological quality both of randomised and non-randomised studies of health care interventions. $J$ Epidemiol Commun Health. 1998;52(6):377-384.

36. Munn J, Sullivan SJ, Schneiders AG. Evidence of sensorimotor deficits in functional ankle instability: a systematic review with metaanalysis. J Sci Med Sport. 2010;13(1):2-12.

37. Ebell MH, Siwek J, Weiss BD, et al. Strength of recommendation taxonomy (SORT): a patient-centered approach to grading evidence in the medical literature. Am Fam Physician. 2004;69(3):548-556.

38. Borenstein M, Hedges L, Higgins J, Rothstein H. Introduction to Meta-Analysis. West Sussex, UK: John Wiley \& Sons, Ltd; 2009.

39. Hozo SP, Djulbegovic B, Hozo I. Estimating the mean and variance from the median, range, and the size of a sample. BMC Med Res Methodol. 2005;5:13.

40. Cohen J. Statistical Power Analysis for the Behavioral Sciences. 2nd ed. Hillsdale, NJ: Lawrence Erlbaum Associates; 1988.

41. Varni JW, Limbers CA, Burwinkle TM. How young can children reliably and validly self-report their health-related quality of life? An analysis of 8,591 children across age subgroups with the PedsQL 4.0 Generic Core Scales. Health Qual Life Outcomes. 2007;5:1.

42. Chia EM, Chia EM, Rochtchina E, Wang JJ, Mitchell P. Utility and validity of the self-administered SF-36: findings from an older population. Ann Acad Med Singapore. 2006;35(7):461-467.

43. Lyons RA, Perry HM, Littlepage BN. Evidence for the validity of the Short-Form 36 Questionnaire (SF-36) in an elderly population. Age Ageing. 1994;23(3):182-184.

44. Jenkinson C, Wright $\mathrm{L}$, Coulter A. Criterion validity and reliability of the SF-36 in a population sample. Qual Life Res. 1994;3(1):7-12.

Address correspondence to Megan N. Houston, PhD, ATC, Keller Army Community Hospital, 900 Washington Road, West Point, NY 10996. Address e-mail to megan.n.houston.ctr@mail.mil. 